\title{
A Ruptured Cystic Artery Pseudoaneurysm with Concurrent Cholecystoduodenal Fistula: A Case Report and Literature Review
}

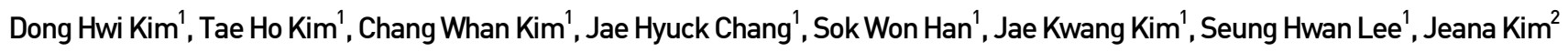 \\ Departments of Internal Medicine ${ }^{1}$ and Hospital Pathology ${ }^{2}$, Bucheon St. Mary's Hospital, College of Medicine, The Catholic University of \\ Korea, Bucheon, Korea
}

\begin{abstract}
Pseudoaneurysms of the cystic artery and cholecystoduodenal fistula formation are rare complications of cholecystitis and either may result from an inflammatory process in the abdomen. A 68-year-old man admitted with acute cholecystitis subsequently developed massive upper gastrointestinal (GI) bleeding. Abdominal computed tomography showed acute calculous cholecystitis and hemobilia secondary to bleeding from the cystic artery. Angiography suggested a ruptured pseudoaneurysm of the cystic artery. Upper GI endoscopy showed a deep active ulcer with an opening that was suspected to be that of a fistula at the duodenal bulb. The patient was managed successfully with multimodality treatment that included embolization followed by elective laparoscopic cholecystectomy. Presently, there is no clear consensus regarding the clinical management of this disease. We have been able to confirm various clinical features, diagnoses, and treatments of this disease through a literature review. A multidisciplinary approach through interagency/interdepartmental collaboration is necessary for better management of this disease. (Korean J Helicobacter Up Gastrointest Res 2018;18:135-141)
\end{abstract}

Key Words: Angiography; Cholecystoduodenal fistula; Pseudoaneurysm

\section{INTRODUCTION}

Gastrointestinal bleeding from the biliary tree, termed "hemobilia," is an uncommon event. A cystic artery pseudoaneurysm is a very rare complication of cholecystitis and is known to cause hemobilia. ${ }^{1}$ Cholecystoenteric fistula is also a rare complication of gallstone disease. ${ }^{1}$ We report here a very rare case of upper gastrointestinal hemorrhage due to rupture of pseudoaneurysm of the cystic artery with concurrent cholecystoduodenal fistula.

\section{CASE REPORT}

A 68-year-old man presented to the emergency room complaining of epigastric pain. He had a history of diabetes, hypertension and GB stones. Until shortly before his presentation, the patient was taking aspirin and clopidogrel and denied any history of trauma or recent surgery.

Received: February 6, 2018 Revised: March 27, 2018 Accepted: March 27, 2018

Corresponding author: Tae Ho Kim

Department of Internal Medicine, Bucheon St. Mary's Hospital, College of Medicine, The Catholic University of Korea, 327 Sosa-ro, Wonmi-gu, Bucheon 14647, Korea Tel: +82-32-340-7017, Fax: +82-32-340-7227, E-mail: drkimtaeho@gmail.com (1) ORCID: https://orcid.org/0000-0003-2015-5176
On clinical examination, he was afebrile and hemodynamically stable. The general physical examination was normal, but there was tenderness and rebound tenderness in the right hypochondrium and epigastrium. The laboratory test results included a white blood cell count of

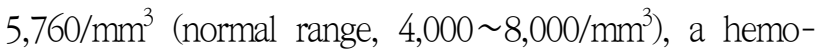
globin level of $10.9 \mathrm{~g} / \mathrm{dL}$ (normal range, $13.0 \sim 18.0 \mathrm{~g} / \mathrm{dL}$ ), and platelet count of $239,000 / \mathrm{mm}^{3}$ (normal range, $140,000 \sim$ $450,000 / \mathrm{mm}^{3}$ ). Blood chemistry showed the following abnormal values: total bilirubin $3.32 \mathrm{mg} / \mathrm{dL}$ (normal range, $0.2 \sim 1 \mathrm{mg} / \mathrm{dL}$ ), aspartate aminotransferase $298 \mathrm{U} / \mathrm{L}$ (normal range, 10 40 U/L), alanine aminotransferase $184 \mathrm{U} / \mathrm{L}$ (normal range, 10 40 U/L), gamma-glutamyltransferase $714 \mathrm{U} / \mathrm{L}$ (normal range, 5 40 U/L), and C-reactive protein $20.8 \mathrm{mg} / \mathrm{L}$ (normal range, $0 \sim 5 \mathrm{mg} / \mathrm{L}$ ). The patient was suspected to have an acute cholecystitis or cholangitis because of the history of GB stones and right upper quadrant abdominal pain. Contrast enhanced computed tomography (CT) was planned for confirmation. After CT imaging, the patient suddenly developed massive hematemesis. His hemoglobin dropped to $6.0 \mathrm{~g} / \mathrm{dL}$, blood pressure decreased to $50 / 30 \mathrm{mmHg}$ and his heart rate was $120 \mathrm{bpm}$ at that time. The CT showed a severely

Copyright $\odot 2018$ Korean College of Helicobacter and Upper Gastrointestinal Research

(a) The Korean Journal of Helicobacter and Upper Gastrointestinal Research is an Open-Access Journal. All articles are distributed under the terms of the Creative Commons Attribution Non-Commercial License (http://creativecommons.org/licenses/by-nc/4.0) which permits unrestricted non-commercial use, distribution, and reproduction in any medium, provided the original work is properly cited. 

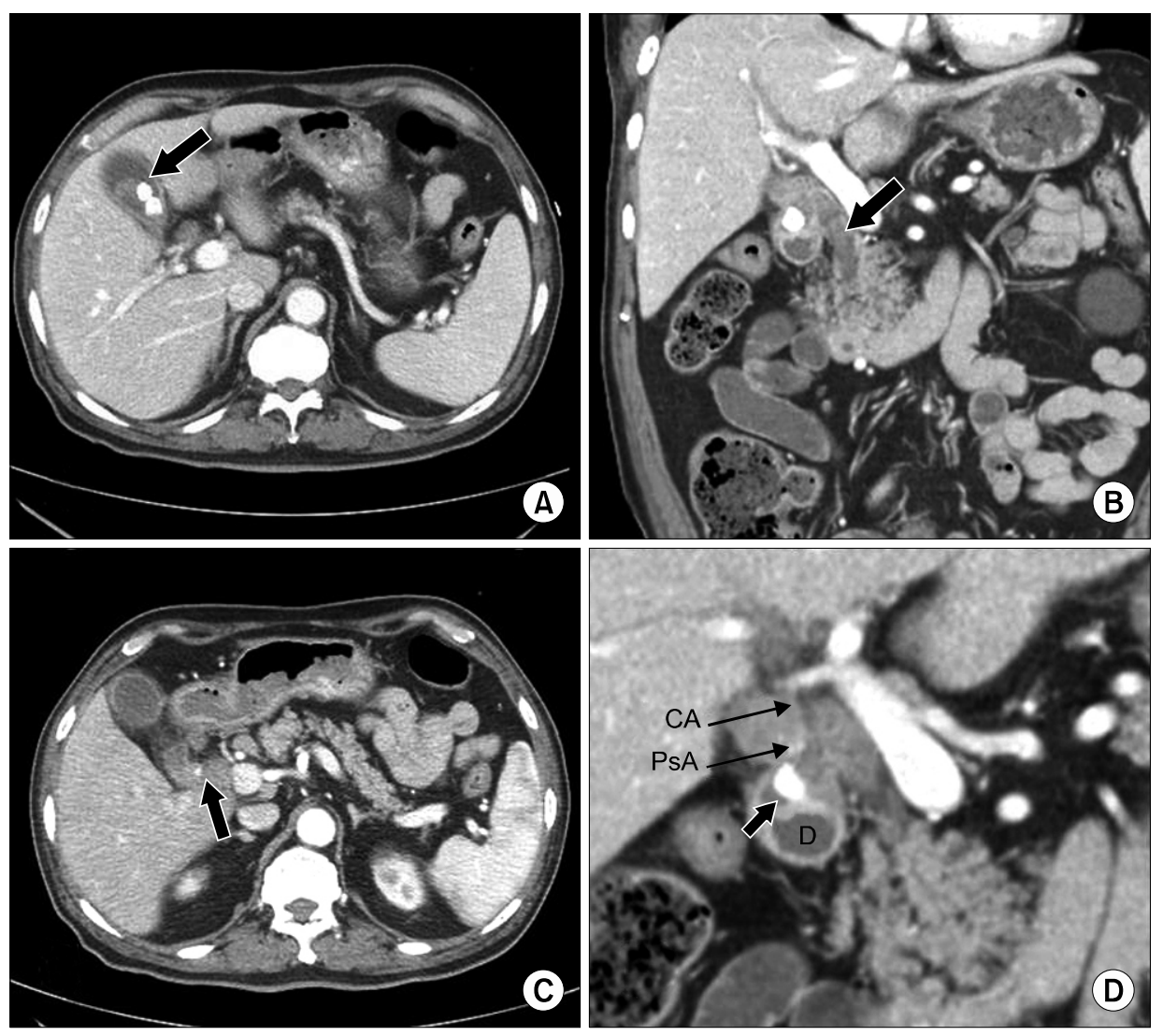

Fig. 1. Abdominal computed tomography (CT) findings. Contrastenhanced CT images show acute calculous cholecystitis with intragallbladder (GB) hemorrhage (arrow) (A), high density material (arrow) filling the common bile duct (hemobilia) (B), a small-sized pseudoaneurysm of the cystic artery (arrow) (C), and a fistulous tract between the GB and the duodenum (cholecystoduodenal fistula) with a stone (arrow) adjacent to the second portion of the duodenum (D). CA, cystic artery; PsA, pseudoaneurysm; D, duodenum. distended GB with two $10 \mathrm{~mm}$ sized-stones and hemobilia due to cystic artery bleeding. In addition, a fistula tract caused by the pressure of a stone adjacent to second portion of duodenum was suspected (Fig. 1).

We assessed the patient's status as hypovolemic shock due to upper GI bleeding. He underwent an emergency angiography to find the bleeding focus after resuscitation with a massive transfusion (14 units of packed red blood cells). Angiography revealed rupture of the small cystic artery PSA originating from the hepatic artery and a suspicion of extravasation of contrast into duodenum (Fig. 2). A Coil embolization was performed to control the bleeding. He then underwent an upper GI endoscopy which showed that the esophagus and stomach were normal and revealed a deep active ulcer $(15 \mathrm{~mm})$ with an opening that was suspected of a fistula formation seen on the anterior inferior surface of the first part of the duodenum (Fig. 3). The patient underwent a follow-up CT scan before surgery. Stones within the GB were found, and the impacted stone in the fistula tract, which was found at

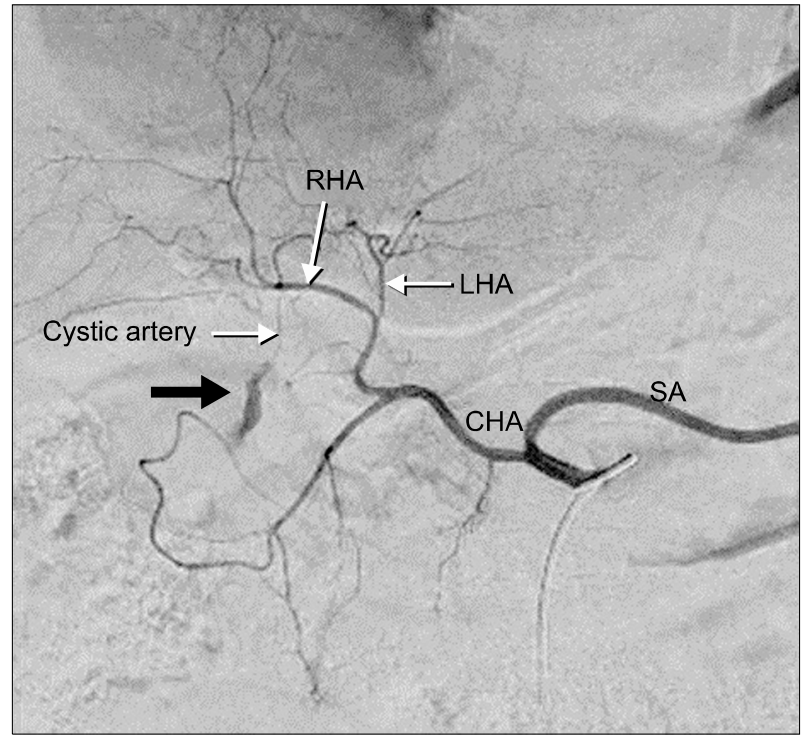

Fig. 2. Angiographic findings. Angiographic images show extravasation from pseudoaneurysm originating from the cystic artery (black arrow). RHA, right hepatic artery; LHA, left hepatic artery; CHA, common hepatic artery; SA, splenic artery. 
the time of diagnosis, was found to be released (Fig. 4). After a few days, the patient underwent an elective laparoscopic cholecystectomy. During the operation, there was severe inflammation and fibrosis within the cystic duct and GB infundibulum, and a severe adhesion was observed between the GB and duodenum. After ligating the cystic artery and the cystic duct with a clip, the GB was separated from the liver bed, and then the primary closure of the cystic duct stump and duodenum was

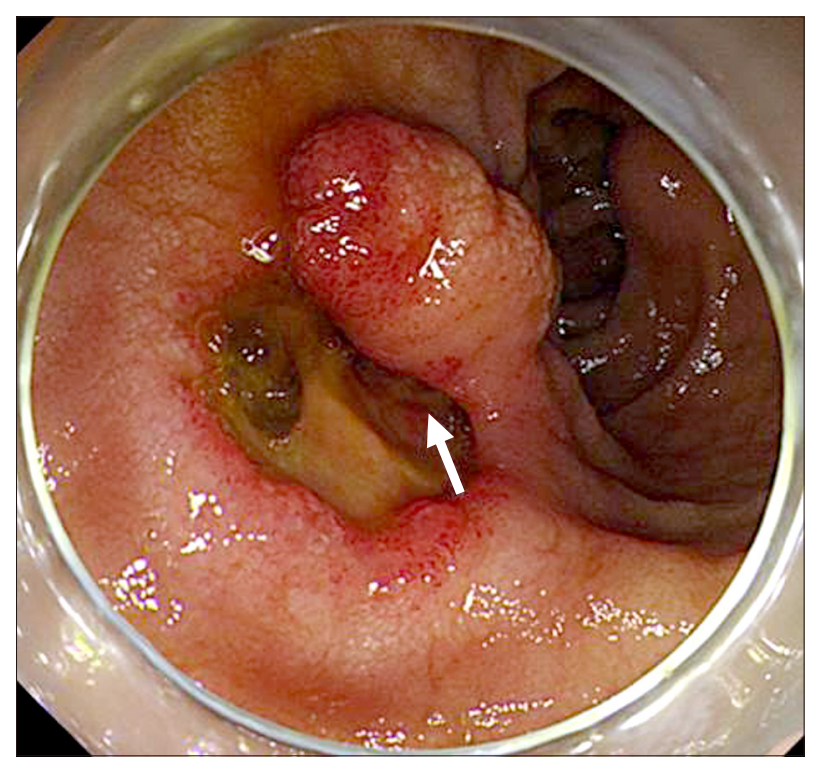

Fig. 3. Endoscopic findings. Endoscopy shows an active duodenal ulcer with an opening (white arrow) that is suspected to be the opening of a fistula located at the duodenal bulb. performed. Histologically, the GB showed focal wall thinning with an erosive mucosal surface, suspicious for the clinical diagnosis of a cholecystoduodenal fistula (Fig. 5). The patient was discharged without complication on the seventh postoperative day.

\section{DISCUSSION}

A PSA of the cystic artery is a very rare cause of hemobilia, and its pathogenesis is unclear. Hemobilia generally presents as upper quadrant pain (biliary colic), obstructive jaundice, and GI hemorrhage (Quincke's triad). Such aneurysms have been thought to occur after inflammatory processes near the vessel and can rupture into the GB, cystic duct or bile duct with resultant hemobilia but rarely rupture into the peritoneal cavity. Most cases reported have been caused by acute calculous cholecystitis except for postoperative complications. Aneurysmal formation can further progress from patient factors such as atherosclerosis, hypertension, bleeding disorder, and vasculitis. ${ }^{1}$ PsA of the cystic artery due to acute cholecystitis is a very rare cause of upper GI bleeding. In a PubMed search of the literature (using key words: pseudoaneurysm, cystic artery, and cholecystitis), only 36 cases have been identified in the English literature. Among these cases, only 27 cases of a cystic artery aneurysm were expressed as a clinical manifestation of a rupture such as GI bleeding and internal hemorrhage.

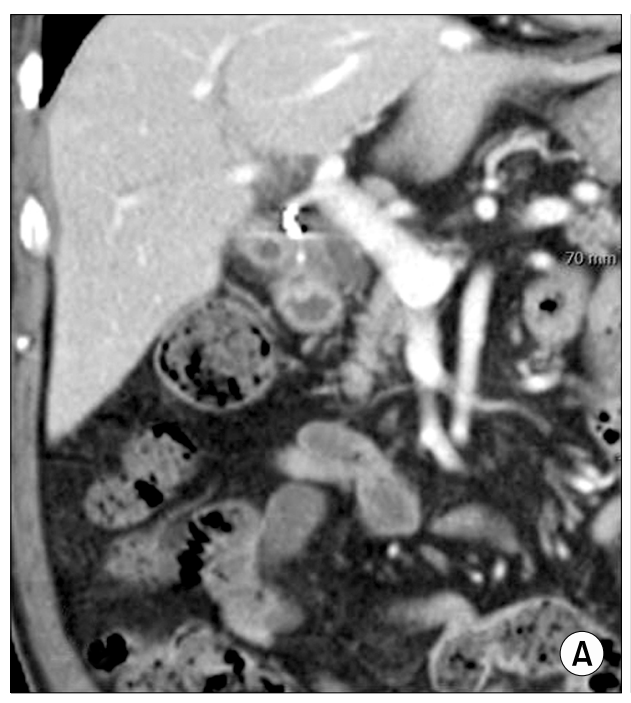

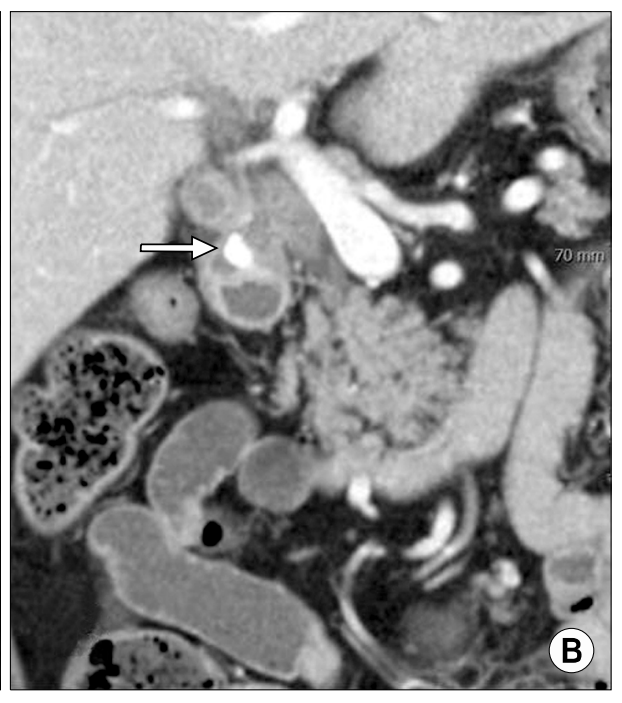

Fig. 4. Follow-up computed tomography (CT) findings. Follow-up CT images show that the impacted stone (arrow) in the fistula tract has been disimpacted (A) compared with an initial CT scan (B). 


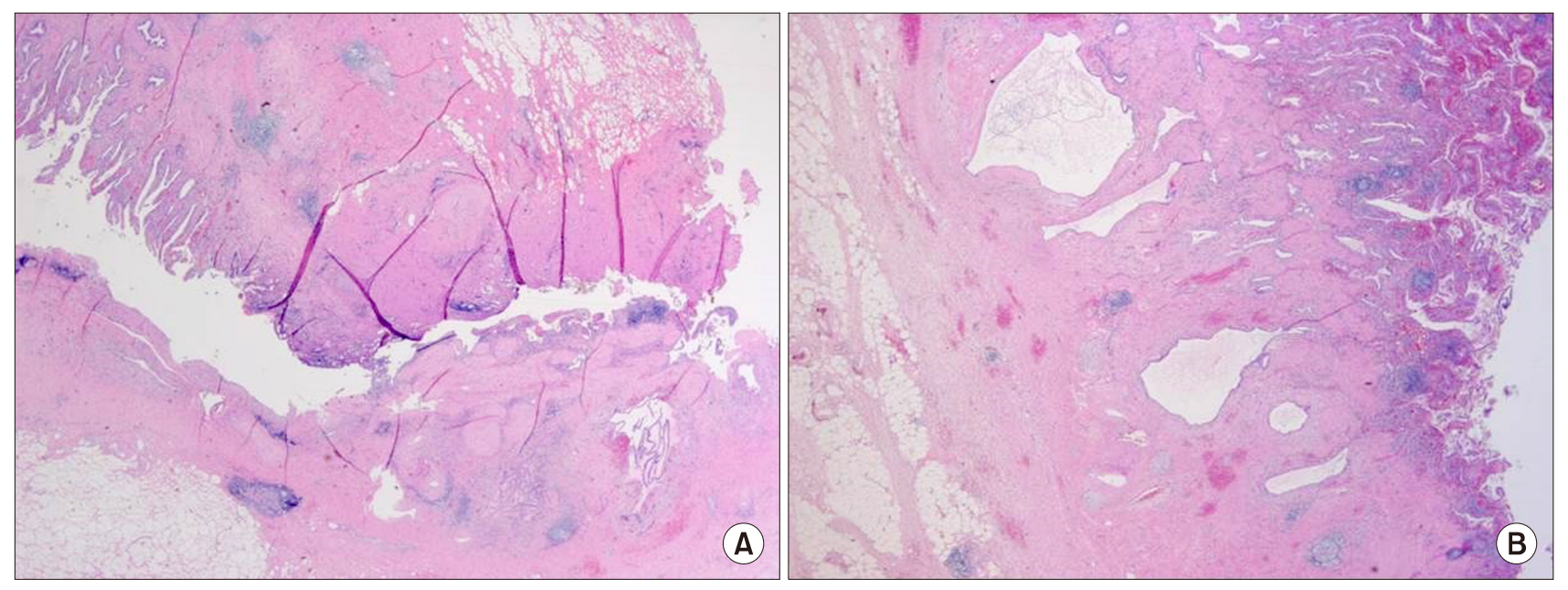

Fig. 5. Histopathological findings $(H \& E, \times 40)$. The gallbladder shows an erosive mucosal surface with chronic inflammation and wall thinning (A) and epithelial proliferation, muscular hypertrophy and intramural diverticula (Rokitansky-Aschoff sinuses) (B).

We reviewed 36 reports on PsA of the cystic artery related to cholecystitis and the results are as follows (Table 1). ${ }^{1-30}$ The mean age of the patients was 67 years, and the sex distribution was 10 males and 26 females. PsA of the cystic artery was found to be $25.0 \%$ (9/36) without rupture, and $75.0 \%$ (27/36) with rupture. In another report, ${ }^{2}$ hemobilia was reported in $45 \%$ of cases in the PsA of the cystic artery, but in $75.0 \%$ (27/36) of cases in this review. GI manifestations of these hemobilia patients were $46.2 \%(12 / 26)$ for melena, $23.1 \%$ (6/26) for hematemesis and $7.7 \%$ (2/26) for hematochezia. Nine of the patients showed no symptoms of GI bleeding. In one case, ${ }^{3}$ rupture of the PSA of the cystic artery resulted in hemoperitoneum with GB perforation, so there were no hemobilia. The incidence of jaundice was 27.8\% (10/36) and the typical three symptoms of hemobilia (Quincke's triad) were reported in $16.7 \%$ (6/36) of the cases reported in this review, compared with $32 \%$ to $40 \%$ reported in other literature. ${ }^{31}$ CT or CT angiography was most frequently used for diagnostic purposes, followed by angiography $(11.1 \%$, 4/36), Ultrasonography (US) (8.3\%, 3/36) and magnetic resonance imaging/magnetic resonance cholangiopancreatography $(8.3 \%, 3 / 36)$, and there was no case in which the PsA of the cystic artery was diagnosed by ultrasound (US) alone. The US value can identify potential aneurysms, but it may not detect small aneurysm. Although celiac or selective hepatic arteriography is the gold standard method for diagnosis, a contrast enhanced CT is the best noninvasive method especially in emergency situations such as acute abdominal bleeding. ${ }^{2,4}$ In this case, rupture of cystic artery PsA was suspected on $\mathrm{CT}$, and subsequent angiography was able to confirm and treat, simultaneously.

Transcatheter arterial embolization (TAE) followed by cholecystectomy was performed in most cases $(41.7 \%$, 15/36). Patients were treated with TAE alone if they were not suitable for surgical candidates due to age or underlying disease, and $25.0 \%(9 / 36)$ cases were treated with surgery alone. There were two cases of an emergency operation due to failure of TAE. ${ }^{5,6}$ Traditionally, surgical ligation has been known to treat this disease. Based on the case reviews, the combination of TAE followed by surgical treatment seems to be the most effective. Recently, embolization of the cystic artery has been reported as effected, with a lower risk of visceral trauma and without a need for general anesthesia. ${ }^{7}$ Like most other cases, we preformed embolization first, followed by an elective laparoscopic cholecystectomy.

In addition, it is a peculiar point that the cystic artery PsA rupture was presented with a cholecystoduodenal fistula in this patient. The creation of a bilioenteric fistula is a very rare complication of GB stones which affects less than $1 \%$ of patients. ${ }^{32}$ The fistula can occur anywhere in the GI tract with the most common location being chol- 
Table 1. Summary of Cases of Cystic Artery Aneurysm Secondary to Acute Cholecystitis

\begin{tabular}{|c|c|c|c|c|c|c|c|c|c|}
\hline No. & Year & 1st author & Age (yr) & Sex & Presentation & $\mathrm{HB}$ & Rup & Diagnosis & Treatment \\
\hline 1 & 2017 & Tapnio $\mathrm{RH}^{7}$ & 91 & $\mathrm{~F}$ & Pain, fever & $\mathrm{Y}$ & Y & CT, US & $\mathrm{TAE}+$ cholecystectomy \\
\hline 2 & 2017 & Tapnio $\mathrm{RH}^{7}$ & 61 & M & Pain, fever & $\mathrm{Y}$ & $\mathrm{Y}$ & CTA & $\mathrm{TAE}+$ cholecystectomy \\
\hline 3 & 2017 & Tapnio $\mathrm{RH}^{7}$ & 91 & M & None & $\mathrm{N}$ & $\mathrm{N}$ & $\mathrm{CT}$ & TAE \\
\hline 4 & 2017 & Zucker B ${ }^{9}$ & 56 & $\mathrm{M}$ & None & $\mathrm{N}$ & $\mathrm{N}$ & & Cholecystectomy \\
\hline 5 & 2017 & Trombatore $\mathrm{C}^{10}$ & 64 & M & $\begin{array}{l}\text { Pain, vomiting, hematemesis, } \\
\text { melena }\end{array}$ & $\mathrm{Y}$ & $\mathrm{Y}$ & $\mathrm{CT}$ & TAE + cholecystectomy \\
\hline 6 & 2016 & Alis $\mathrm{D}^{11}$ & 36 & M & Pain & $\mathrm{N}$ & $\mathrm{N}$ & CT & TAE \\
\hline 7 & 2015 & Loizides $S^{12}$ & 61 & $\mathrm{~F}$ & Pain, vomiting & $\mathrm{N}$ & $\mathrm{N}$ & $\mathrm{CT}$ & Cholecystectomy \\
\hline 8 & 2015 & $\begin{array}{l}\text { Muñoz- } \\
\quad \text { Villafranca } C^{13}\end{array}$ & 74 & M & Pain, melena & $\mathrm{Y}$ & $\mathrm{Y}$ & CT, MRI & TAE \\
\hline 9 & 2014 & Glaysher MA ${ }^{1}$ & 86 & M & Pain, vomiting, melena & $\mathrm{Y}$ & Y & CT & Cholecystectomy \\
\hline 10 & 2014 & Kulkarni $V^{14}$ & 55 & M & Pain, jaundice, melena & $\mathrm{Y}$ & $\mathrm{Y}$ & CT, MRCP & $\mathrm{TAE}+$ cholecystectomy \\
\hline 11 & 2013 & Nana GR ${ }^{15}$ & 74 & M & Pain, jaundice, hematemesis & $\mathrm{Y}$ & $\mathrm{Y}$ & CTA & $\mathrm{TAE}+$ cholecystectomy \\
\hline 12 & 2013 & Nana $G^{15}$ & 79 & $\mathrm{~F}$ & Weight loss, melena, jaundice & $\mathrm{Y}$ & $\mathrm{Y}$ & $\mathrm{CT}$ & TAE \\
\hline 13 & 2013 & Suzuki S ${ }^{16}$ & 85 & $\mathrm{~F}$ & Pain, jaundice, Mirizzi syndrome & $\mathrm{N}$ & $\mathrm{N}$ & CTA, US & $\mathrm{TAE}+$ cholecystectomy \\
\hline 14 & 2013 & Fung $\mathrm{AK}^{3}$ & 64 & M & Pain & $\mathrm{N}$ & $\mathrm{Y}$ & CTA & Cholecystectomy \\
\hline 15 & 2013 & Priya $\mathrm{H}^{5}$ & 22 & M & $\begin{array}{l}\text { Pain, jaundice, melena, } \\
\text { hematemesis }\end{array}$ & $\mathrm{Y}$ & $\mathrm{Y}$ & Angiography & Cholecystectomy \\
\hline 16 & 2012 & Chong $\mathrm{JJ}^{17}$ & 56 & $\mathrm{M}$ & Pain, fever, hematemesis & $\mathrm{Y}$ & Y & CT & $\mathrm{TAE}+$ cholecystectomy \\
\hline 17 & 2011 & Siddiqui $\mathrm{NA}^{18}$ & 58 & M & Pain, jaundice & $\mathrm{Y}$ & $\mathrm{Y}$ & $\mathrm{CT}$ & $\mathrm{TAE}+$ cholecystectomy \\
\hline 18 & 2010 & Ahmed I ${ }^{19}$ & 54 & M & Pain & $\mathrm{Y}$ & $\mathrm{Y}$ & CT & $\mathrm{TAE}+$ cholecystectomy \\
\hline 19 & 2010 & Hague $\mathrm{J}^{20}$ & 83 & M & Pain & $\mathrm{Y}$ & $\mathrm{Y}$ & $\mathrm{CT}$ & TAE \\
\hline 20 & 2010 & Hague $\mathrm{J}^{20}$ & 79 & M & Pain & $\mathrm{Y}$ & $\mathrm{Y}$ & CTA & TAE+cholecystectomy \\
\hline 21 & 2010 & Hague $\mathrm{J}^{20}$ & 83 & M & Pain, melena & $\mathrm{Y}$ & $\mathrm{Y}$ & CTA & TAE \\
\hline 22 & 2010 & Nkwam N ${ }^{21}$ & 71 & M & Pain, vomiting & $\mathrm{N}$ & $\mathrm{N}$ & CTA & Cholecystectomy \\
\hline 23 & 2010 & Desai $\mathrm{AU}^{22}$ & 78 & $\mathrm{~F}$ & Pain, vomiting, melena & Y & $\mathrm{Y}$ & $\mathrm{CT}$ & TAE \\
\hline 24 & 2009 & Mullen $\mathrm{R}^{23}$ & 75 & $\mathrm{~F}$ & Pain, melena & $\mathrm{Y}$ & $\mathrm{Y}$ & CT & TAE \\
\hline 25 & 2009 & Mullen $\mathrm{R}^{23}$ & 82 & M & Pain & $\mathrm{N}$ & $\mathrm{N}$ & $\mathrm{CT}$ & TAE \\
\hline 26 & 2008 & Machida $\mathrm{H}^{4}$ & 71 & M & Pain & $\mathrm{N}$ & $\mathrm{N}$ & CT & Cholecystectomy \\
\hline 27 & 2008 & Shimada $\mathrm{K}^{24}$ & 68 & M & Jaundice & $\mathrm{Y}$ & $\mathrm{Y}$ & $\mathrm{CT}$ & Hepatectomy \\
\hline 28 & 2007 & Akatsu $\mathrm{T}^{25}$ & 58 & M & Pain, jaundice & $\mathrm{Y}$ & $\mathrm{Y}$ & MRI & Cholecystectomy \\
\hline 29 & 2007 & Saluja $\mathrm{SS}^{26}$ & 43 & $\mathrm{~F}$ & Melena, hematemesis & $\mathrm{Y}$ & $\mathrm{Y}$ & CT, US & TAE + cholecystectomy \\
\hline 30 & 2006 & Pérez JL ${ }^{27}$ & 77 & $\mathrm{~F}$ & Hypotension, anemia & $\mathrm{Y}$ & $\mathrm{Y}$ & Angiography & TAE \\
\hline 31 & 2006 & Lee $\mathrm{JW}^{8}$ & 72 & $\mathrm{~F}$ & Pain, vomiting, hematochezia & $\mathrm{Y}$ & $\mathrm{Y}$ & $\mathrm{CT}$ & TAE + cholecystectomy \\
\hline 32 & 2006 & Joyce $\mathrm{MR}^{28}$ & 58 & M & Pyrexia, melena & $\mathrm{Y}$ & $\mathrm{Y}$ & $\begin{array}{l}\text { Explore } \\
\text { laparotomy }\end{array}$ & Cholecystectomy \\
\hline 33 & 2004 & Gutiérrez $\mathrm{G}^{6}$ & 66 & $\mathrm{~F}$ & Pain, anemia, hematochezia & $\mathrm{Y}$ & $\mathrm{Y}$ & $\mathrm{CT}$ & Cholecystectomy \\
\hline 34 & 2002 & Maeda $\mathrm{A}^{29}$ & 62 & $\mathrm{M}$ & Pain & $\mathrm{N}$ & $\mathrm{N}$ & Angiography & TAE + cholecystectomy \\
\hline 35 & 1999 & Delgadillo $X^{2}$ & 28 & M & Pain, jaundice, hematemesis & $\mathrm{Y}$ & $\mathrm{Y}$ & $\mathrm{CT}$ & TAE \\
\hline 36 & 1996 & Nakajima $\mathrm{M}^{30}$ & 72 & M & Pain, jaundice, melena & $\mathrm{Y}$ & $\mathrm{Y}$ & CT, angiography & Cholecystectomy \\
\hline
\end{tabular}

HB, hemobilia; Rup, rupture; F, female; M, male; Y, yes; N, no; CT, computed tomography; US, ultrasonography; CTA, CT angiography; MRI, magnetic resonance imaging; MRCP, magnetic resonance cholangiopancreatography; TAE, transcatheter arterial embolization.

ecystoduodenal $(\sim 60 \%)$ and cholecystocolic $(17 \%)$ and cholecystogastric and choledochoduodenal areas $(5 \%){ }^{33}$ The incidence of a cholecystoduodenal fistula is reported to occur during $0.29 \%$ to $0.42 \%$ of cholecystectomy procedures. ${ }^{34,35}$ The most common cause of cholecystoduodenal fistula is a gallstone. ${ }^{36} \mathrm{~A}$ fistula is often diagnosed during surgery. However, there are several cases $^{34}$ that were diagnosed before surgery due to symptoms of gall- stone ileus and cholangitis. The classic treatment of a cholecystoenteric fistula is cholecystectomy with a primary closure of the fistula. ${ }^{34}$ Except our case, there was only one case report ${ }^{5}$ with two rare complications of cholecystitis that occurred simultaneously worldwide. In 36 case reviews, fistulas were found only in 3 cases, and the types of fistulas included cholecystoduodenal fistula, ${ }^{5}$ cholecystojejunal fistula ${ }^{1}$ and cholecystocolonic fistula. ${ }^{8}$ 
Even though a PsA of the cystic artery and cholecystoenteric fistula are very rare, they should be considered as a complication of calculous cholecystitis, and a PsA of the cystic artery should be included in the differential diagnosis of hemobilia. There is no clear consensus yet on the clinical management of this disease. We have been able to confirm various clinical features, diagnoses, and treatments of this disease through a literature review. A CT scan and angiography are useful for diagnosis, and TAE followed by cholecystectomy seems to be best for treatment of this disease. Additionally, TAE alone therapy is also considered an effective temporary option in the subset of these patients who are unable to undergo immediate surgical management. A multidisciplinary collaboration between radiologists and surgeons is the key-point to improve management of these patients.

\section{REFERENCES}

1. Glaysher MA, Cruttenden-Wood D, Szentpali K. A rare cause of upper gastrointestinal haemorrhage: ruptured cystic artery pseudoaneurysm with concurrent cholecystojejunal fistula. Int J Surg Case Rep 2014;5:1-4.

2. Delgadillo X, Berney T, de Perrot M, Didier D, Morel P. Successful treatment of a pseudoaneurysm of the cystic artery with microcoil embolization. J Vasc Interv Radiol 1999;10: 789-792.

3. Fung AK, Vosough A, Olson S, Aly EH, Binnie NR. An unusual cause of acute internal haemorrhage: cystic artery pseudoaneurysm secondary to acute cholecystitis. Scott Med J 2013; 58:e23-e26.

4. Machida H, Ueno E, Shiozawa S, et al. Unruptured pseudoaneurysm of the cystic artery with acute calculous cholecystitis incidentally detected by computed tomography. Radiat Med 2008;26:384-387.

5. Priya H, Anshul G, Alok T, et al. Emergency cholecystectomy and hepatic arterial repair in a patient presenting with haemobilia and massive gastrointestinal haemorrhage due to a spontaneous cystic artery gallbladder fistula masquerading as a pseudoaneurysm. BMC Gastroenterol 2013;13:43.

6. Gutiérrez G, Ramia JM, Villar J, Garrote D, Ferron A, Ruiz E. Cystic artery pseudoaneurism from an evolved acute calculous cholecystitis. Am J Surg 2004;187:519-520.

7. Tapnio RH, Kolber MK, Shukla PA, Berkowitz E. Transcatheter embolization of cystic artery pseudoaneurysms secondary to acute cholecystitis. Vasc Endovascular Surg 2017;51:498-500.

8. Lee JW, Kim MY, Kim YJ, Suh CH. CT of acute lower GI bleeding in chronic cholecystitis: concomitant pseudoaneurysm of cystic artery and cholecystocolonic fistula. Clin Radiol 2006;
61:634-636.

9. Zucker B, Walsh U, Nott D. Laparoscopic treatment of cystic artery pseudoaneurysm in the presence of calculous cholecystitis. Ann R Coll Surg Engl 2017;99:e183-e184.

10. Trombatore C, Scilletta R, Bellavia N, et al. Acute hemobilia from a pseudoaneurysm of the cystic artery arising from the left hepatic artery: case report and literature review. Int J Surg Case Rep 2017;37:60-64.

11. Alis D, Ferahman S, Demiryas S, Samanci C, Ustabasioglu FE. Laparoscopic management of a very rare case: cystic artery pseudoaneurysm secondary to acute cholecystitis. Case Rep Surg 2016;2016:1489013.

12. Loizides S, Ali A, Newton R, Singh KK. Laparoscopic management of a cystic artery pseudoaneurysm in a patient with calculus cholecystitis. Int J Surg Case Rep 2015;14:182-185.

13. Muñoz-Villafranca C, García-Kamirruaga Î, Góme-García P, et al. Pseudoaneurysm of the cystic artery: an uncommon cause of upper gastrointestinal bleeding in a case of xanthogranulomatous cholecystitis. Rev Esp Enferm Dig 2015;107:375-376.

14. Kulkarni V, Deshmukh H, Gupta R. Pseudoaneurysm of anomalous cystic artery due to calculous cholecystitis. BMJ Case Rep 2014. doi: 10.1136/bcr-2014-207069.

15. Nana GR, Gibson M, Speirs A, Ramus JR. Upper gastrointestinal bleeding: a rare complication of acute cholecystitis. Int J Surg Case Rep 2013;4:761-764.

16. Suzuki S, Saito Y, Nakamura K, et al. Unruptured cystic artery pseudoaneurysm accompanied by Mirizzi syndrome: a report of a case. Clin J Gastroenterol 2013;6:490-495.

17. Chong JJ, O'Connell T, Munk PL, Yang N, Harris AC. Case of the month \#176: pseudoaneurysm of the cystic artery. Can Assoc Radiol J 2012;63:153-155.

18. Siddiqui NA, Chawla T, Nadeem M. Cystic artery pseudoaneurysm secondary to acute cholecystitis as cause of haemobilia. BMJ Case Rep 2011. doi:10.1136/bcr.07.2011.4480.

19. Ahmed I, Tanveer UH, Sajjad Z, Munazza B, Azeem UD, Basit S. Cystic artery pseudo-aneurysm: a complication of xanthogranulomatous cholecystitis. Br J Radiol 2010;83:e165-e167.

20. Hague J, Brennand D, Raja J, Amin Z. Cystic artery pseudoaneurysms in hemorrhagic acute cholecystitis. Cardiovasc Intervent Radiol 2010;33:1287-1290.

21. Nkwam N, Heppenstall K. Unruptured pseudoaneurysm of the cystic artery associated with acute calculus cholecystitis. J Surg Case Rep 2010;2010:4.

22. Desai AU, Saunders MP, Anderson HJ, Howlett DC. Successful transcatheter arterial embolisation of a cystic artery pseudoaneurysm secondary to calculus cholecystitis: a case report. J Radiol Case Rep 2010;4:18-22.

23. Mullen R, Suttie SA, Bhat R, Evgenikos N, Yalamarthi S, McBride $\mathrm{KD}$. Microcoil embolisation of mycotic cystic artery pseudoaneurysm: a viable option in high-risk patients. Cardiovasc Intervent Radiol 2009;32:1275-1279.

24. Shimada K, Sakamoto Y, Esaki M, Kosuge T. Pseudoaneurysm of the cystic artery associated with xanthogranulomatous cholecystitis. Dig Surg 2008;25:8-9. 
25. Akatsu T, Tanabe M, Shimizu T, et al. Pseudoaneurysm of the cystic artery secondary to cholecystitis as a cause of hemobilia: report of a case. Surg Today 2007;37:412-417.

26. Saluja SS, Ray S, Gulati MS, Pal S, Sahni P, Chattopadhyay TK. Acute cholecystitis with massive upper gastrointestinal bleed: a case report and review of the literature. BMC Gastroenterol 2007;7:12.

27. Pérez-Castrillón JL, Mendo M, Calero H. Hemorrhage into the gallbladder caused by pseudoaneurysm of the cystic artery. Endoscopy 2006;38 Suppl 2:E50.

28. Joyce MR, Donnolly M, O'Shea L, Jeffers M, O'Riordain D. Pseudoaneurysm of the cystic artery: a diagnostic dilemma and rare cause of haemobilia. Ir J Med Sci 2006;175:81.

29. Maeda A, Kunou T, Saeki S, et al. Pseudoaneurysm of the cystic artery with hemobilia treated by arterial embolization and elective cholecystectomy. J Hepatobiliary Pancreat Surg 2002;9: 755-758.

30. Nakajima M, Hoshino H, Hayashi E, et al. Pseudoaneurysm of the cystic artery associated with upper gastrointestinal bleeding. J Gastroenterol 1996;31:750-754.

31. Sousa HT, Amaro P, Brito J, et al. Hemobilia due to pseudoa- neurysm of the cystic artery. Gastroenterol Clin Biol 2009; 33:80-82.

32. Masannat YA, Caplin S, Brown T. A rare complication of a common disease: Bouveret syndrome, a case report. World J Gastroenterol 2006;12:2620-2621.

33. Mavroeidis VK, Matthioudakis DI, Economou NK, Karanikas ID. Bouveret syndrome-the rarest variant of gallstone ileus: a case report and literature review. Case Rep Surg 2013;2013:839370.

34. Aguilar-Espinosa F, Maza-Sánchez R, Vargas-Solís F, GuerreroMartínez GA, Medina-Reyes JL, Flores-Quiroz PI. Cholecystoduodenal fistula, an infrequent complication of cholelithiasis: our experience in its surgical management. Rev Gastroenterol Mex 2017;82:287-295.

35. Duzgun AP, Ozmen MM, Ozer MV, Coskun F. Internal biliary fistula due to cholelithiasis: a single-centre experience. World J Gastroenterol 2007;13:4606-4609.

36. Bilhartz L. Acute acalculous cholecystitis, adenomyomatosis, cholesterolosis, and polyps of the gallbladder. In: Sleisenger MH, Fordtran JS, eds. Gastrointestinal disease pathophysiology, diagnosis, management. Philadelphia: WB Saunders, 1993: 1858-1868. 